\title{
Oppositional defiant disorder: current insight
}

This article was published in the following Dove Press journal: Psychology Research and Behavior Management

\author{
Abhishek Ghosh' \\ Anirban Ray ${ }^{2}$ \\ Aniruddha Basu' \\ 'Drug De-addiction and Treatment \\ Centre, Department of Psychiatry, \\ Postgraduate Institute of Medical \\ Education and Research (PGIMER), \\ Chandigarh, ${ }^{2}$ Department of \\ Psychiatry, Institute of Psychiatry, \\ Institute of Post Graduate Medical \\ Education and Research, Kolkata, India
}

Correspondence: Abhishek Ghosh Drug De-addiction and Treatment Centre, Department of Psychiatry, Postgraduate Institute of Medical Education and Research (PGIMER), Sector 12, Chandigarh 1600I2, India Email ghoshabhishek12@gmail.com

\begin{abstract}
Oppositional defiant disorder (ODD) is diagnosed broadly on the basis of frequent and persistent angry or irritable mood, argumentativeness/defiance, and vindictiveness. Since its inception in the third Diagnostic and Statistical Manual of Mental Disorders, epidemiological and longitudinal studies have strongly suggested a distinct existence of ODD that is different from other closely related externalizing disorders, with different course and outcome and possibly discrete subtypes. However, several issues, such as symptom threshold, dimensional versus categorical conceptualization, and sex-specific symptoms, are yet to be addressed. Although ODD was found to be highly heritable, no genetic polymorphism has been identified with confidence. There has been a definite genetic overlap with other externalizing disorders. Studies have begun to explore its epigenetics and gene-environment interaction. Neuroimaging findings converge to implicate various parts of the prefrontal cortex, amygdala, and insula. Alteration in cortisol levels has also been demonstrated consistently. Although a range of environmental factors, both familial and extrafamilial, have been studied in the past, current research has combined these with other biological parameters. Psychosocial treatment continues to be time-tested and effective. These include parental management training, school-based training, functional family therapy/ brief strategic family therapy, and cognitive behavior therapy. Management of severe aggression and treatment of co-morbid disorders are indications for pharmacotherapy. In line with previous conceptualization of chronic irritability as a bipolar spectrum abnormality, most studies have explored antipsychotics and mood stabilizers in the management of aggression, with limited effects.
\end{abstract}

Keywords: externalizing disorders, nosology, genetics

\section{Introduction}

The diagnosis of oppositional defiant disorder (ODD) is broadly based on frequent and persistent angry or irritable mood, argumentativeness/defiance, and vindictiveness. ${ }^{1}$ It is "qualitatively" different from conduct disorder (CD), which talks about impingement of others' rights and violation of age-appropriate social norms. Both of these together are known as disruptive behavior disorders (DBDs), the concept of which was conceived almost 50 years ago. Over the years, there have been changes in the clinical, psychosocial, and biological understanding of ODD. There have been noteworthy changes in diagnostic schemes. Numerous psychosocial risk factors have been identified. Biological factors, especially with the help of newer neuroimaging techniques, and brain substrates for oppositional behaviors have been explored. Studies have been conducted to find the best possible preventions and interventions.

\section{Search methodology}

Gathering the data for this work involved the use of electronic databases and manual searching of relevant publications or cross-references. The electronic search included 
PubMed, Google Scholar, Scopus, and Ovid. Electronic cross-searches of key references yielded other relevant material. The search terms used in various combinations were disruptive behavior disorder, ODD, conduct disorder, aggression, irritability and children, mood disorders, disruptive mood dysregulation (MD), drug or alcohol use, externalizing and children or adolescent, internalizing and children or adolescent, outcome, course, treatment, management, imaging, genetics, neurobiology, neuropsychology, psychosocial, stress, family, and parenting. Data inclusion for this review was guided by the following principles: We included studies published after 2000 (except for the initial development of nosology) till April 2017. As we aimed for a narrative review, we were overinclusive and did not restrict data inclusion by any standardized methodology. The intent was to include as much research and as many aspects as possible. Wherever applicable, the strengths and the limitations of the cited research are also discussed.

\section{Nosology of ODD Evolution of ODD}

The concept of DBDs in children and adolescents was first proposed in the Diagnostic and Statistical Manual of Mental Disorders (DSM)-II ${ }^{2}$ as three distinct diagnoses, said to be originated from three different environmental factors and based on cluster or factor analysis of delinquent boys: runaway reaction, unsocialized aggressive reaction, and group delinquent reaction. Few line descriptors were discussed. ${ }^{3,4}$ However, there were no diagnostic criteria as such, and hence, the reliability of these diagnoses was questionable.

In the DSM-III, ${ }^{5}$ there was a paradigm shift in the conceptualization of mental disorders, and diagnostic criteria were proposed. The diagnosis of ODD as oppositional disorder was introduced. The diagnostic criteria, mostly behavioral without affective features, consisted of violation of minor rules (as opposed to violation of rights of others and major societal norms in CD), temper tantrums, argumentativeness, provocative behavior, and stubbornness. The diagnostic threshold was decided to be two of five symptoms, which had to be present for more than 6 months. CD could not be diagnosed with ODD, as the prevailing notion was that ODD would be present in a major proportion of $C D$ patients. With publication of the DSM-III, although there was a modest improvement in interrater reliability, the validity of ODD diagnosis and its diagnostic threshold faced severe criticism. ${ }^{6}$ Because of the lack of empirical support, the diagnosis of ODD was criticized as medicalization of normative child behavior, ${ }^{7}$ especially in the absence of aggressive CD symptoms. ${ }^{8}$ Moreover, ODD was found to produce only minor levels of impairment and was difficult to differentiate from CD. ${ }^{9}$ To address these issues, the DSM-IIIR proposed the addition of two criteria: spiteful/vindictiveness and angry and resentful attitude. To differentiate ODD from normative behavior, the frequency of occurrence of ODD symptoms must be disproportionate to the age and developmental stage of the child. A field trial was conducted to establish the reliability and validity of the proposed DSM-IIIR diagnosis of ODD. It showed the current diagnosis had reasonable discrimination power and reliability. However, one proposed ODD symptom (bullying others) was eliminated on theoretical grounds. ${ }^{10}$ The DSM-IIIR retained the convention that $\mathrm{CD}$ preempted the diagnosis of ODD, as it was noticed in this trial that only $16 \%$ of CD subjects did not meet the criteria for ODD. This field trial had predominantly male children, and there was a scarcity of preschoolers and adolescents. Therefore, the generalizability of results was questioned. Moreover, use of individual clinician diagnosis as the gold standard was condemned because of its uncertain reliability. A field trial for the DSM-IV took cognizance of some of these criticisms, and included children and adolescents with wide age range. ${ }^{11}$ However, three-quarters of the population were male. Except dropping one criterion (swearing) from ODD because of its limited clinical utility, and subsequently changing the cutoff from five of nine to four of eight criteria, no other changes were made. Most evidence suggested a dose-response relationship between symptom severity and functional impairment, and thus, the diagnostic threshold was said to be arbitrary. ${ }^{12}$ Additionally, a study by Cohen et al showed that the diagnostic stability of ODD increased with increasing severity (OR of diagnostic stability for mild ODD 3.2, moderate ODD 6, and severe ODD 8.3). ${ }^{13}$

Therefore, the clinical utility of severity dimension was established with reasonable certainty. Moreover, with the new set of criteria, almost $50 \%$ of individuals who fulfilled the diagnosis of CD did not meet the criteria for ODD. However, the hierarchical rule of diagnosis was retained, despite evidence to the contrary.

The ICD9 diagnosis of ODD was vaguely specified, but it included the DSM symptoms of ODD and CD in a common group labeled "CDs". The ICD10 maintained similar principles, but specified the rules for diagnosis. The criteria set for CD in the ICD10 consisted of a rough combination of DSM-IV CD and ODD symptoms. However, important differences exist in terms of diagnostic principles. As per the ICD $10^{14}$ scheme, the presence of any four (of 23) symptoms would constitute a diagnosis of ODD, and three more severe symptoms are required for diagnosis of $\mathrm{CD}$. Therefore, the 
scheme suggests a continuum between ODD and CD, but the hierarchical rule for diagnosis still exists. The continuum model has distinct advantages over the categorical approach in DSM. ODD symptoms become less common between childhood and adolescence, while CD behavior, especially covert behavior, comes up. ${ }^{15}$ Therefore, it is possible that in an intermediate stage, an individual might not fulfill either CD or ODD diagnosis, as per the DSM-IV. However, the ICD10 might allocate the diagnosis of ODD subtype in such a scenario. In fact, the Great Smoky Mountains study showed that it would be possible to diagnose CDs in about $40 \%$ more cases when ICD10 criteria were used instead of DSM. Therefore, the ICD10 approach seems to be more sensitive, but the diagnostic concordance between the two systems is uncertain. ${ }^{16}$

\section{Cumulative evidence base for current nosology}

Sex specificity of DSM-IV diagnostic criteria

As already pointed out, the diagnostic validity of DBDs was questioned among girls. To attend to the issue, Keenan et al studied a large community sample of girls $(n=2,451)$ longitudinally from the age 7-15 years. Only about half of those girls who had met the criteria for $\mathrm{CD}$ at any phase also met the diagnosis for ODD. ${ }^{17}$ This observation once again questioned the preemptive diagnosis of CD, even in girls. This study also identified a linear relation between the number of criteria met and the degree of severity, and threw doubt on the threshold of four criteria in girls. It suggested a severity dimension that was present in DSM-IV, but seldom used in clinical or research settings. The Great Smoky Mountains study, in which there was substantial representation of girls, showed in girls that ODD did not confer increased risk for the development of $\mathrm{CD}$; rather, it was associated with increased risk of continued ODD, depression, and anxiety. However, in boys ODD was a strong risk factor for $\mathrm{CD}$. This study demonstrated differential outcomes of ODD in boys and girls. ${ }^{16}$ Therefore, the question on sex influence in the diagnosis of ODD is still alive.

\section{Hierarchical diagnosis of CD}

Up till the DSM-IV, despite evidence from cross-sectional studies, dual diagnosis of CD and ODD could not be considered. To settle this issue convincingly, a longitudinal study was conducted by Rowe et al, which included both sexes and spanned the age range of 9-21 years. ${ }^{18}$ The transition from ODD to CD was much less than anticipated, and nearly half of all children with a diagnosis of $\mathrm{CD}$ did not fulfill any prior diagnosis of ODD. However, ODD diagnosis was found to be a risk factor for development of $\mathrm{CD}$, and the significance persisted even when subthreshold CD symptoms were controlled for. Combining data from three longitudinal data sets, Burke et al showed that a substantive proportion of youths with adolescent-onset CD did not have ODD diagnosis in their childhood. These studies put forth strong evidence against the previous hierarchical approach for the diagnosis of CD and ODD, and suggest that though they may lie in a continuum, they are two distinct disorders. ${ }^{19}$

\section{Subtypes of ODD}

Phenomenologically, there are two distinct features in ODD: one characterized by affective symptoms of irritability, temper tantrums, and resentful attitude, and the other tapping the features of defiance like vindictiveness and arguing. Two longitudinal studies have explored the significance of these two dimensions. Kolko and Pardini examined a clinicbased sample of 177 children aged 6-11 years and followed them for the next 3 years. ${ }^{20}$ The study demonstrated that the irritability facet of ODD was associated with posttreatment internalizing problems, whereas the facet of defiance (eg, vindictiveness) predicted CD symptoms or diagnosis of delinquent behavior, in other words, externalizing problems. This result was replicated in another study with much larger sample size and longer duration of follow-up. ${ }^{18}$ This study derived a two-factor solution of ODD symptoms, namely, irritability and "headstrong" symptoms, and showed that irritability symptoms predicted anxiety disorders more strongly than headstrong symptoms (arguing with adults, defying adults' requests). Another recent study conducted in twin pairs $(n=1,225)$ by Mikolajewski et $\mathrm{al}^{21}$ found consistent evidence of an "irritable" dimension predicting internalizing problems and a headstrong/hurtful dimension of substance-use disorder symptoms. Additionally, shared genetic risk between the dimension and the disorders was demonstrated. Three dimensions of ODD were also proposed in one cross-sectional general population-based study in the UK. It found an additional dimension, "hurtful", and found it to be associated with callous traits and aggressive symptoms of CD. ${ }^{22}$ Therefore, underlying subtypes or dimensions of ODD are well recognized, but the actual number of facets is still uncertain.

\section{Dimensional conceptualization of ODD}

A dimensional approach to ODD could be regarded as dimensions within the diagnosis or dimensions among various other diagnoses. The former type is more applicable in clinical settings, whereas the latter type might be more useful for 
theoretical and research purposes. An example of the former type is the severity dimension, which was acknowledged in the DSM-IV. However, studies have cast doubt on its validity and demonstrated higher predictive validity of severity of various forms of delinquent acts or individual symptoms. ${ }^{13,23,24}$ On a similar line, there was uncertainty regarding the threshold fixed in the DSM-IV. In a birth cohort in New Zealand consisting of nearly 1,000 individuals, the need for a dimensional conceptualization was highlighted. This study showed that subclinical levels of ODD predicted a wide range of negative outcomes, including internalizing problems. ${ }^{25}$ Another study by Burke et al also showed that a modified diagnosis of ODD consisting of subclinical symptoms of both ODD and CD could identify children with significant impairment in all domains. ${ }^{19}$ Both these studies suggest a continuum rather than a categorical approach for DBDs could be considered, in line with the ICD10 scheme of diagnosis.

\section{Delimitation from other disorders}

The construct of irritability in children and adolescents is not restricted to ODD. The US National Institute of Mental Health proposed a concept of severe mood dysregulation (MD) (SMD), a syndrome characterized by chronic abnormal levels of anger or sadness, symptoms of hyperarousal manifested as insomnia or agitation, and heightened physical or verbal reactivity. SMD has been found to predict development of anxiety and depressive disorders. ${ }^{22,26}$ This outcome is akin to that found in ODD, with a predominant irritability dimension. The question is: Do these refer to the same construct? The DSM- $5^{1}$ has added the diagnosis of disruptive MD disorder (DMDD) as a separate diagnostic entity, under the mood-disorder group. The criteria for DMDD are similar to SMD, absent the component of hyperarousal. Critiques have pointed out the inadequate literature to substantiate the diagnosis of DMDD and to differentiate it from ODD. ${ }^{27}$ High co-occurrence of ODD and DMDD has been demonstrated in both cross-sectional and longitudinal studies and young and older children. ${ }^{28,29} \mathrm{~A}$ study in a community mental health clinic with individuals aged 6-18 years showed that youth with DMDD had very high odds (OR 53.8) of having ODD and displayed higher rates of comorbidity with $\mathrm{CD}$ and attention-deficit/hyperactivity disorder (ADHD). ${ }^{30}$ Another recently conducted study on a generalpopulation sample of children of $6-12$ years old $(n=665)$ found that more than $90 \%$ with DMDD had ODD, and $66 \%$ of ODD children had symptoms of DMDD. Moreover, the presence of comorbid psychopathology (anxiety, depression, CD, ADHD) did not increase the risk of DMDD independently of ODD. Both these studies from treatment settings and community samples asserted that DMDD cannot be differentiated from ODD phenomenologically. ${ }^{31}$

Another common childhood disorder that needs to be differentiated from ODD is ADHD. Behavioral deviance is common to both conditions. However, the core symptoms of ADHD, hyperactivity, and inattention differ ostensibly from the irritability and argumentative symptoms of ODD. Nevertheless, because of substantial co-morbidity (30-50\%) between ADHD and ODD, distinction between the disorders is a matter of research. ${ }^{32,33}$ There are two broad models to understand this comorbidity: the correlated risk-factor model, which posits that both these disorders have shared risk factors, and the developmental precursor model, which suggests symptoms of ADHD lead to ODD. A study in young children aged 3-6 years demonstrated that the anger-irritability dimension of ODD could be explained by the correlated risk model, whereas the co-occurrence of the argumentativenessdefiance dimension and ADHD could be elucidated by the developmental precursor model. ${ }^{34}$ A school-based study from South Korea $(n=2,693)$ showed that distinctive temperamental and emotional/behavioral characteristics were associated with ODD and that these were independent of ADHD. ${ }^{35}$ In another study to explore temperamental antecedents of ODD, a longitudinal observation was carried out in young children in a representative general population as part of the Avon longitudinal study of parents and children. ODD was found to be preceded by temperaments of both emotionality (RR 1.34) and activity (RR 1.39). However, the presence of comorbidity with ODD increased the predictive power. Early temperament of emotionality strongly predicted ODD with comorbid internalizing disorders, whereas ODD and ADHD were predicted by high activity levels. The findings suggest that early emotionality and activity differentially affect features of ODD and co-occurring psychopathology. ${ }^{26}$ The functional implications of ODD and ADHD might also differ. In a study among adolescents to understand the effect of ODD vs ADHD symptoms in bullying/victimization, it was observed that ODD symptoms were more strongly linked with both bullying and victimization. Though the effect was found in both sexes, the association in boys was stronger. ${ }^{36}$

Despite high co-occurrence, ODD can be differentiated from ADHD, not only by clinical presentation but also by differential antecedents and functional consequences.

\section{Impact on current nosology}

Removal of hierarchical approach in diagnosis

Till the DSM-IV, CD and ODD figured as exclusions for each other. In fact, CD diagnosis would take precedence over 
ODD in the presence of both. However, as already discussed, in line with the cumulative evidence against the hierarchical diagnosis, the DSM-5 has removed the CD exclusion from ODD and vice versa. The upcoming edition of the ICD11 is also likely to follow suit.

\section{Adding different facets to diagnostic criteria for ODD}

As the recent evidence suggests that there could be more than one dimension to ODD, the DSM-5 divided the diagnostic criteria into three groups - angry/irritable mood, argumentative/ defiant behavior, and vindictiveness - without any emphasis on any of these particular dimensions for diagnosis. However, it has kept the number and description of symptoms and the diagnostic threshold mostly unchanged.

\section{Delimitation from normative behavior}

Unlike the DSM-IV, which was emphatic only about persistence of symptoms for more than 6 months, the DSM-5 has emphasized both persistence and frequency of behavior. For children below 5 years of age, the symptoms must be present on most days, and for those who are $\geq 5$ years, symptoms must be present at least once per week (except for vindictiveness: twice within the past 6 months). By doing this, the DSM-5 has made an attempt to differentiate disorder from normative behavior and is attentive to the developmental aspects.

\section{Delimitation from other disorders}

The DSM-5 has added the exclusion of DMDD, in addition to the disorders that were already mentioned in the previous edition. As already discussed, the diagnostic overlap between ODD and DMDD is significant, and its exclusion might lead to spurious diagnosis of either conditions. The ICD11 is going to take a different approach to avert this problem. Two ODD subtypes are recognized in the ICD11 - individuals with or without chronic irritability or anger - and it does not recognize DMDD as a separate diagnostic entity. ${ }^{37}$ In their review, Evans et al noted, "This solution is more consistent with the available evidence and is a better fit with global public health considerations such as harm/benefit potential, clinical utility, and cross-cultural applicability." ${ }^{38}$

\section{Proposing a different severity dimension}

The DSM-5 has moved away from symptom count-based severity and has proposed severity based on pervasiveness of symptoms. When symptoms are present in only one setting, the condition is to be considered mild ODD, whereas symptoms in more than two settings are labeled severe ODD. Moderate falls in between. Although the evidence for this severity dimension is lacking, symptom count-based severity has been found not to be clinically useful. ${ }^{20}$ Therefore, the new metric for severity might be a welcome step to stimulate clinicians and researchers to use it.

Some issues remain unaddressed. First, sex-specific symptoms or cutoffs for the diagnosis have not been considered. Second, the diagnostic threshold remains similar to the previous systems, despite evidence to the contrary. ${ }^{19,25}$ Third, the severity dimension according to the pervasiveness of symptoms is impressionistic, rather than empirical. Fourth, the grouping of ODD and CD with impulse-control disorders in the DSM-5 is not well understood. The ICD11 will take a different approach. According to its present draft, ODD and CD will be grouped under "Disruptive behavior and dissocial disorders". More research would be needed to settle these issues. Figure 1 depicts the current conceptual understanding of ODD.

\section{Etiopathological influences Individual-level factors}

ODD was initially conceptualized as a behavioral problem. It is still not considered by many to be a true psychiatric disorder. However, ODD has been shown to have a lot of biological correlates. A lot of studies in this field have included CD/aggression/ $\mathrm{DBD}$ as their area of interest. ADHD as a comorbidity has been accepted in some studies. Keeping the changing nosology of ODD in mind, this is not unexpected. As it is a non-Mendelian multifactorial disorder with polygenic inheritance, looking for an endophenotype that can act as a biomarker is justified. ${ }^{39}$ To do so, cross-cutting of related disorders may be needed, as suggested in Research Domain Criteria guidelines. ${ }^{40}$

\section{Genetics}

\section{Genetic association and linkage studies}

According to an older study, ODD has $61 \%$ heritability. ${ }^{41}$ ODD shares $50 \%$ of its genes with CD. However, it does not have any unique component of genetic predisposition that is not shared by other psychopathologies. ${ }^{42}$ One familybased linkage study of ADHD and comorbidities identified strong links among ADHD and ODD, ADHD and CD, ODD, and CD. Significant linkage results were obtained at $8 \mathrm{q} 24$. Suggestive values of linkage were obtained at 2p21-22.3, 6q23.3, 14q21.1, 17p12, 17q25.1, and 19p13.2 in children with ODD comorbidity. ${ }^{43}$

Though more robust, hypothesis-free gene association studies like genome-wide association studies or exome 


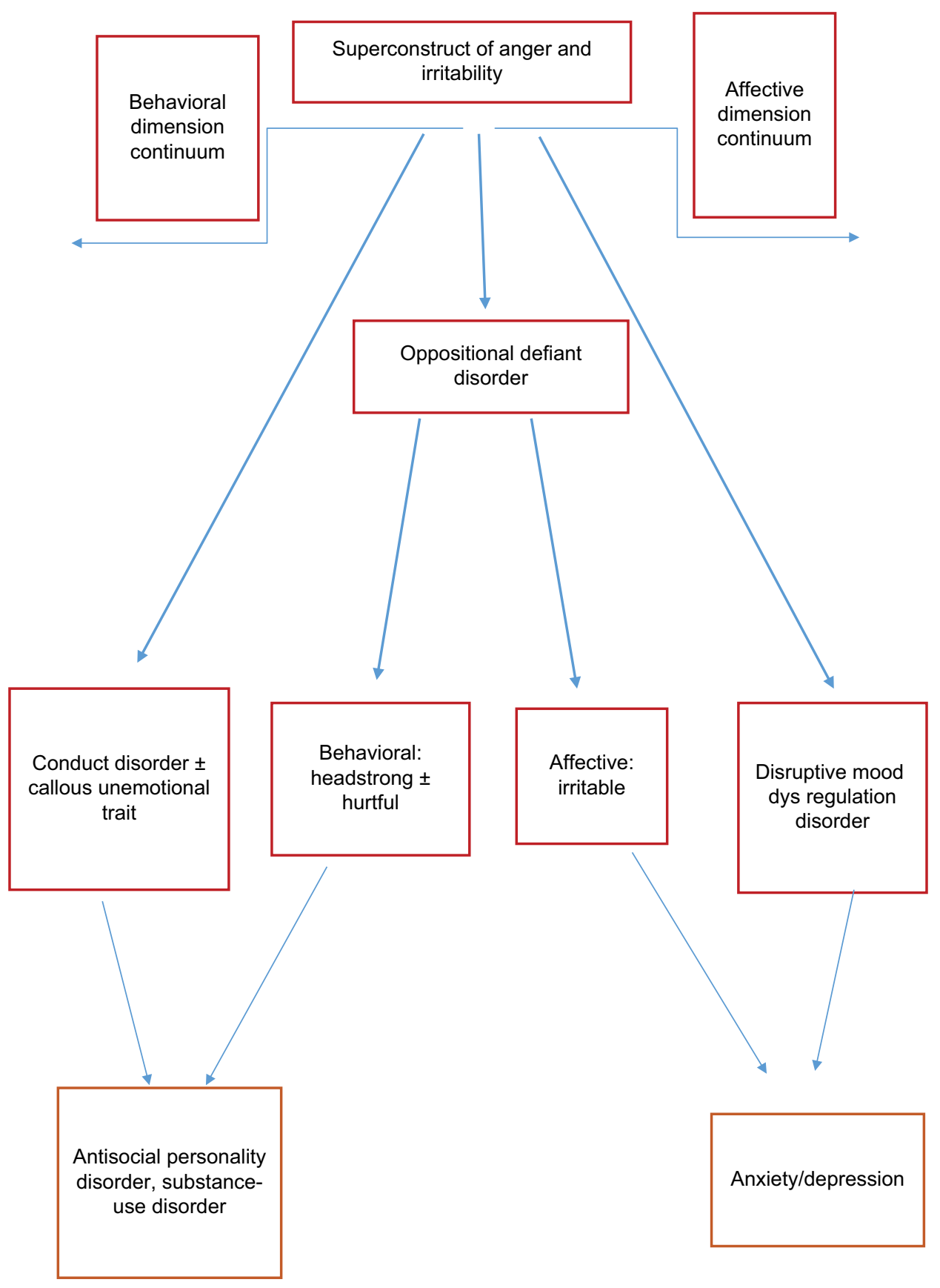

Figure I Conceptual understanding of disruptive behavior disorders.

sequencing have not shown much yield. One study with ADHD with $\mathrm{CD}$ comorbidities found 54 suggestive loci, but none was clearly significant. ${ }^{44}$ Another recent study pointed out the 2p12 loci and AVPR1A gene as significantly associated with aggression in early and middle childhood, but needs to be replicated. ${ }^{45}$

Compared to the hypothesis-free approach, the hypothesisdriven candidate gene approach has had at least some success in predicting conduct symptoms of childhood. ${ }^{46}$ Several single- nucleotide polymorphisms of the GABRA2 gene are associated with subclinical externalizing behavior. ${ }^{47}$ Mainly dopaminergic and serotonergic system genes and hormone regulator genes have been explored for association with aggression. ${ }^{48} \mathrm{MAOA}$ promoter upstream variable number tandem repeat (VNTR) low-activity allele and short-allele of 5-HTTLPR in the SLC6A4 gene have been found to be associated with aggressive behavior. ${ }^{49}$ Recently, 86 genes were identified for putative causative factors for aggression in rare genetic disorders from 
the Online Mendelian Inheritance of Man resource,${ }^{50}$ though the clinical usefulness of this is doubtful.

\section{Gene $\times$ environment and epigenetics}

One twin study from Minnesota Twin Family Study register showed that ODD dimensions had significant additive genetic influence. The headstrong dimension had significant shared and unshared environmental influences, whereas the irritable dimension had some nonadditive genetic effects and unshared environmental effects. These dimensions either independently or in combination predict various internalizing and externalizing problems in the adolescence. Shared environment was the weakest contributor. ${ }^{21} \mathrm{~A}$ recent metaanalysis showed around $50 \%$ variance of $\mathrm{CD}$ comes from additive genetic effects. In this study, along with unshared environmental components, there was a significant shared environmental component, eg, parenting practices or neighborhood. ${ }^{51}$ This echoed another older study, which showed that though underlying externalizing factors are mainly genetically predicted, when CD is considered, it has $26 \%$ variance accounted for by shared environmental factors. ${ }^{52}$

Gene-environment interaction studies have posited that genetic variance in conduct symptoms is greater or more expressed in less restrictive environments. ${ }^{46}$ One metaanalysis showed that carriers of a putative susceptibility allele were more responsive to family-based intervention than noncarriers, though this needs reconfirmation. ${ }^{53}$ Of a DRD4 48-base pair VNTR, the seven-repeat allele predicted externalizing symptoms. ${ }^{54}$ It also predicted good response with better, sensitive parenting and worse response with poor parenting than a four-repeat allele, which varied less with change in quality of parenting. ${ }^{55,56}$

Epigenetic-based studies have mainly focused on differential methylation in the OXTR gene and cytokine genes. ${ }^{46}$ Cecil et al showed that maternal psychopathology and substance abuse increased methylation in offspring in and around the $O X T R$ gene during birth, and also excess methylation in $O X T R$ predispose for callous unemotional traits in adolescence. ${ }^{57}$ Future studies may resort to dimensional approaches, as opposed to categorical approaches, and aggregate genetic risk concepts to solve type I errors due to multiple singlenucleotide polymorphisms and manage multiple genetic effects of small size. ${ }^{46}$

\section{Neuroimaging research}

Explanatory models of ODD/CD mostly focus on executive functions (EFs). The division of EFs into "hot" and "cool" is important in etiopathological research of externalizing disorders. ${ }^{58}$ Hot EF comprises motivational, affective, and emotional aspect of cognition, ${ }^{59}$ whereas cool EF focuses on inhibition, planning, working memory, and flexibility, which are basically top-down control mechanisms of cognition. ${ }^{60}$ The amygdala, anterior cingulate cortex, insula, and orbitofrontal cortex are responsible for hot EF functioning, whereas the dorsolateral prefrontal cortex and cerebellum control cool EF. ${ }^{61}$ Some areas contribute to control both types of function, eg, the precuneus. ${ }^{58}$

Recent meta-analyses of structural studies measuring cortex volume by voxel-based morphometry showed that volume reductions in the left amygdala, insula, and frontal gyrus were associated with $\mathrm{ODD} / \mathrm{CD} \cdot{ }^{58,62-64}$ Other studies have also pointed out reduced volume in the amygdala, anterior insula, anterior cingulate cortex, and medial prefrontal cortex. ${ }^{65}$

The structural covariance method that assesses cortical thickness and correlations among different areas of the cortex is particularly suited to neurodevelopmental disorders. ${ }^{66}$ With that technique, it has been shown that both adolescenceonset and childhood-onset CD are of neurodevelopmental origin but separate, as they differ from healthy controls in the opposite direction. While the childhood-onset type has significantly more transcortical correlations, the adolescentonset type has significantly fewer correlations than healthy controls. ${ }^{67}$ Across studies in DBD, surface-based morphometry by FreeSurfer software ${ }^{68}$ has shown reduced thickness in the ventromedial prefrontal cortex, superior temporal cortex, and angular gyrus. ${ }^{65} \mathrm{ODD} / \mathrm{CD}$ children have a 10\%-13\% reduction in cortical thickness at the whole-brain level. ${ }^{69}$

Functional magnetic resonance imaging (fMRI) during hot EF tasks consistently points toward abnormalities in activation of the amygdala and insula. Though not identified in any individual studies, meta-analysis suggests abnormal activation of the left fusiform area. Functional studies focusing on cool EF in ODD/CD children are fewer, but implicate only the precuneus as an area with activation abnormalities. As such, hot EF areas like the amygdala and striatum are most strongly implicated in ODD. ${ }^{58}$ Most fMRI studies have shown hypoactivation of the amygdala, ${ }^{70,71}$ except a few ${ }^{72}$ during emotional stimuli. This difference may be explained by individual differences in emotional regulation among DBD groups, but emotional regulation has not yet been tested through imaging studies. ${ }^{65}$

Other imaging techniques, such as diffusion tensor imaging, have shown the uncinate fasciculus to be involved consistently, but though some have shown higher diffusiontensor measures, others have shown lowered measures. ${ }^{73-75}$ Also, no significant change has been reported. ${ }^{76}$ Further 
studies are needed in this area. The default-mode network (DMN) of resting-state fMRI includes the medial prefrontal cortex, posterior cingulate cortex, precuneus, and medial temporal lobe. The DMN determines broad attention to the external environment, along with internal mentation of the person. A recent study showed that DMN in CD children was particularly reduced in the posterior cingulate cortex, precuneus, and temporal regions, along with its connection with surrounding structures. ${ }^{77}$ Though ADHD is highly comorbid with ODD, there is functional dissociation between these two disorders with respect to fMRI studies, whereas there is hot EF involvement in ODD, and ADHD has more abnormalities in the cool EF system. ${ }^{78}$

As discussed already, a subgroup of subjects with ODD developed mood disorders later in life. ${ }^{18,20}$ Though less than conclusive, structural neuroimaging in pediatric mood disorders has shown some promise in differentiating unipolar from bipolar mood disorders. A recent systematic review reported higher deep white-matter abnormalities in pediatric bipolar disorders, as opposed to gray matter (basal ganglia and hippocampus) volume reduction in unipolar depression. Moreover, these are speculated to be trait markers, ie, preexisting brain abnormalities. ${ }^{79}$ Therefore, these might aid in differentiating mood disorders from ODD and may also predict conversion to mood disorders later in life.

\section{Neurophysiological and neuroendocrine studies}

Autonomic nervous system function assessed by basal heart rate and electrodermal activity is found to be reduced in adolescents with aggression. ${ }^{80}$ The hypothalamic-pituitary axis measured by basal cortisol levels is also reduced in children showing antisocial behavior. ${ }^{81}$ These measures signify the stress sensitivity of the person. Severe ODD children are known to have low basal heart rate and low cortisol levels, but it has also been observed that variability among groups is very high and anxiety thought to be a possible explanation of that variability. ${ }^{82}$ One study explored that possibility and checked an ODD/CD + anxiety group across normal controls and an ODD/CD - anxiety group. The study also evaluated three phases of cortisol stress response: basal (before the stressor), reactivity (during the stressor), and recovery (after the stressor). It showed the ODD/CD - anxiety group had low basal and low reactivity-phase cortisol levels than the other two groups, but the ODD/CD + anxiety group had an impaired stress-recovery phase, ie, it took longer time for cortisol to come down to baseline after the stressor had stopped. ${ }^{83}$ This was also endorsed by "internalizing disorder" research, where high basal cortisol at age 6 years predicted high reactivity of cortisol and poor recovery at age 9/10 years, which in turn was associated with internalizing disorders. ${ }^{84}$ Reduced serotonin has long been associated with aggression in children. ${ }^{85,86}$ It can have some effect in antisocial personality disorder. ${ }^{87}$

\section{Neuropsychological studies}

On the conceptual front, consequence (reward/punishment) processing of a behavior, along with problem solving and cognitive control, is deficient in DBD children. As CD and ODD children are not affected by this deficiency at the same level, separate assessment of both groups may be needed. ${ }^{88}$ However, neuropsychological studies in the ODD group have shown mixed results. One reason for that may have been inclusion of ADHD comorbidity and CD children, and another reason may be taking ODD as a unitary concept and not being sensitive enough to the possibility of differences in neuropsychological problems across dimensions. ${ }^{89}$ Recently, the DSM-5 proposed three dimensions or clusters of symptoms in ODD syndrome: angry/irritable mood, headstrong, and hurtful/vindictiveness. Recent studies have also focused on identifying underlying factor structures in ODD and obtained two- or three-factor solutions. ${ }^{22,90}$ Along these lines, one recent study found differential neuropsychological afflictions in ODD children. When controlled for ADHD, delay aversion predicted oppositional and antagonistic behavior. Working memory and sustained attention negatively predicted negative affective symptoms, but interestingly better response inhibition predicted more affective symptoms. This is possible if the ODD spectrum includes an anxiety-related component, which is instrumental for more response inhibition. Also, it gives rise to an affective component of the ODD spectrum. Sustained attention also predicted oppositional and antagonistic symptoms, but this was due solely to an ADHD component. ${ }^{89}$ Emotion regulation is also considered a key cognitive component. Both proactive and reactive aggression in children is associated with emotion regulation difficulty. ${ }^{91}$

\section{Psychosocial factors}

Conceptualized as a behavior disorder, ODD is known to have significant environmental causation. Family factors, such as familial psychopathology, poor disciplinary practices, maltreatment and neglect, prenatal risk factors, single parenthood, family disharmony, dissolution, low social class, and poverty, are known to be significantly associated with disruptive behaviors. Extrafamilial causes, such as poor and congested neighborhood, deviant peer groups, peer rejection, and significant life stressors, also have significant negative 
effects on children's behavior. Good parenting practices, attachment with school, strict supervision, and a close and trusted relationship with a trustworthy adult are protective factors against deviant behavior. Recent studies and reviews have also reiterated the same. ${ }^{65,92,93}$

Recent studies have focused more on gene-environment interactions, as already described in this review. An early study showed polymorphism giving rise to low expression of the $M A O A$ gene moderated the pathway from child maltreatment to delinquent behavior. ${ }^{94}$ Genes and environment also showed significant correlation (gene environment correlation [ $\mathrm{rGE}]$ ). It may be "evocative rGE", where individuals' heritable trait elicit a particular environmental response. One recent study showed rejection by prosocial peers was more common for a child with disruptive behavior, which in turn begets more deviant behavior from the rejected child. ${ }^{92}$ The "active rGE" individual seeks and chooses a particular environment, like the genetically predisposed child seeks delinquent peer groups. There is also "passive rGE", where the individual's genes and environment correlate, as parents provide both. ${ }^{48}$ Figure 2 illustrates shared genetic and environmental factors and their interactions that might be implicated in the development of ODD.

\section{Treatment}

While externalizing symptoms are mainly genetically determined according to family studies, CD and DBD have significant environmental impacts, especially the unshared type, such as peer group and life experiences. ${ }^{41}$ Shared environment has not been significantly implicated in child development. Behavioral correlation of two adopted children in the same family hovers near zero. ${ }^{95}$ Shared environment has significant impact in children with CD. ${ }^{42}$ Parenting practices are the most amenable and easily approached target in the management of ODD. Psychosocial management is the most studied in oppositional and conduct problem in children. ${ }^{96}$

\section{Psychosocial management}

Available psychosocial therapies can be subclassified into parental management training (PMT), parenting/schoolbased training, functional family therapy, brief strategic

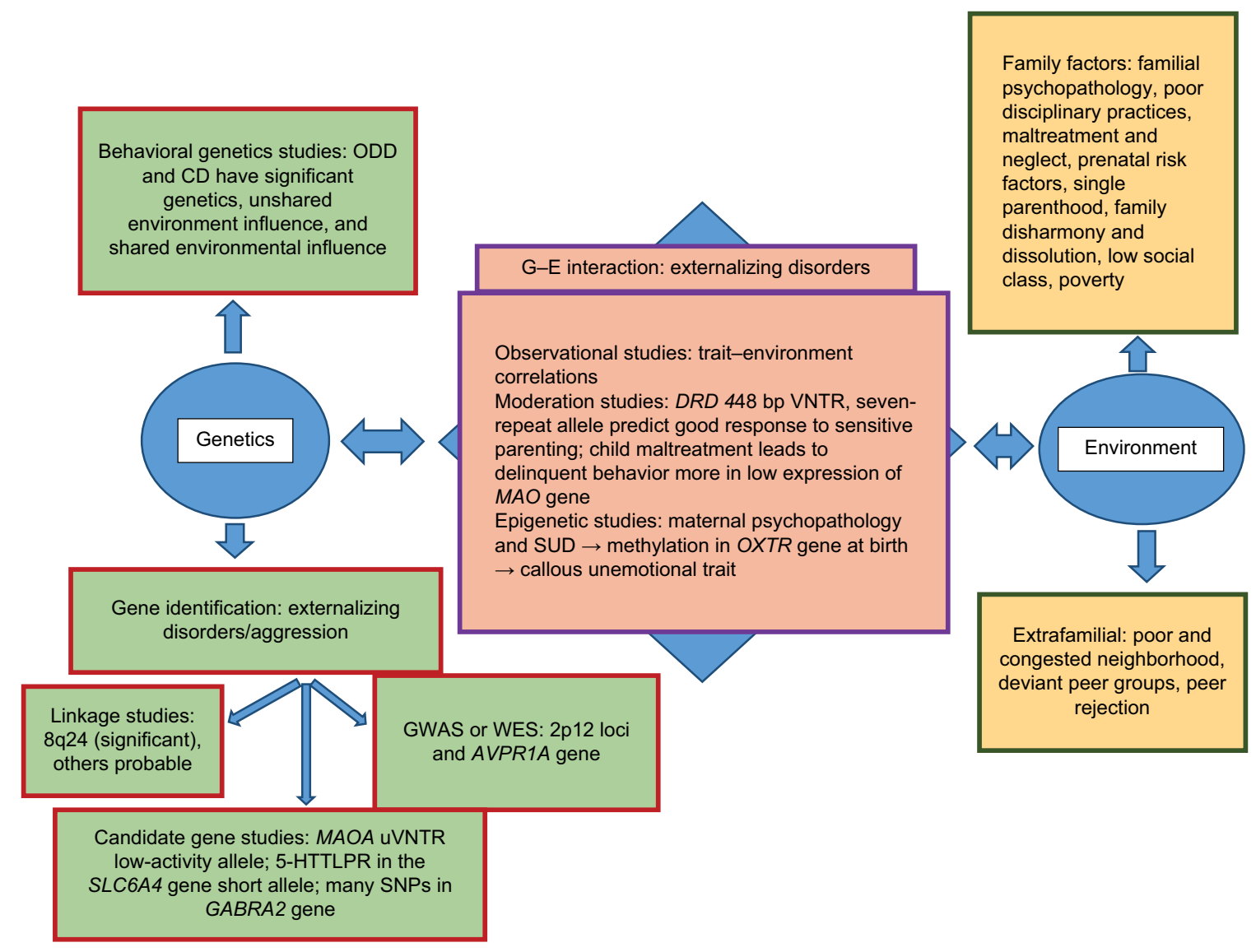

Figure 2 Etiopathogenesis of ODD.

Note: Shared genetic and environmental factors with other externalizing disorders or traits and also the role of gene-environment (G-E) interaction in pathogenesis. Abbreviations: ODD, oppositional defiant disorder; CD, conduct disorder; SUD, substance-use disorder; uVNTR, upstream variable number tandem repeat; GWAS, genome-wide association study; WES, whole-exome sequencing; SNPs, single-nucleotide polymorphisms. 
family therapy, cognitive behavior therapy (CBT) imparted in individual and group formats, multisystemic therapy, and multidimensional therapy in the foster-care setting. ${ }^{96}$ While multicomponent treatment approaches including parentgroup programs are the treatment of choice in aggression with young children $>8$ years of age, older children benefit more from family-based and multicomponent approaches like brief strategic family therapy and multisystemic therapy, according to Center for Education and Research on Mental Health Therapeutics. ${ }^{97,98}$

PMT includes quality time with the child and differential reinforcement strategies to give proper direction to the child's motivation. It focuses on parenting skills. Though more effective with smaller children, components of positive parenting practices like the Triple $\mathrm{P}$ model can be effective with adolescence as well. ${ }^{99}$ Classic PMT models like the Oregon model or others like Kazdin or Berkley are effective. ${ }^{96,100,101}$ Parent-child interaction therapy includes videobased monitoring and feedback that can make the training of parents easier. ${ }^{102}$ Some models also include school-based interventions that help to extend gains in good behavior to the school setting, eg, Good Behavior Game or Incredible Years. ${ }^{96,103,104}$ All these techniques are effective in changing behavior, but programs can vary in effectiveness and in different areas of improvements. ${ }^{105}$

Functional family therapy postulates that problem behavior plays some functional role in family equilibrium, and modification in family functioning can change the behavior problem. Brief strategic family therapy also resorts to a similar principle, but the process of intervention is different. ${ }^{96}$ When the child is slightly older, CBT in different formats is a very useful component of the treatment of DBD. First on this list is an anger-coping program. ${ }^{106}$ The Coping Power program has an additional parent component to the anger-coping program. Problem-solving skills training and perspective-taking are other components of an effective CBT model for aggressive children. ${ }^{107-109}$

Multisystemic therapy incorporates peer interventions, social interventions, and family, school, and individual interventions to address holistically all the components responsible for problem behavior in children. Multidimensional treatment with foster care ensures multiple protective factors, such as reinforcing environment, structured day, strict supervision, and prosocial peers. ${ }^{96}$ These parenting programs can be effective across economic classes and ethnic variation, even without necessary adaptation. ${ }^{101,110}$

In a recent meta-analysis of psychosocial treatments of disruptive disorders, there were two "well-established" treatments in adolescents involving the juvenile justice system. ${ }^{111}$ They were multisystemic therapy and Treatment Foster Care Oregon (formerly multidimensional treatment foster care). These treatment models proved significantly effective in more than one well-conducted trial by more than one research group. Two group-based interventions in the CBT model - aggression replacement training + positive peer culture (equipping youth to help one another) and solution-focused group program - with adolescents in conflict with the law proved to be likely efficacious in more than one effective and well-conducted trial, but by a single research group. Similarly, functional family therapy with adolescents in conflict with the law and multisystemic therapy with disruptive children not in conflict with the law were found to be "probably efficacious" as they were effective in good-quality trials, but not proven across research groups. Two BT- or parenting skill-based models (Familias Unidas and nonviolent resistance with disruptive children), one CBT-based module of "cognitive mediation" with juvenile justice involving children, and two models with combined BT and CBT (rational-emotive BT disruptive behavior and STRIVE [support to reunite, involve, and value each other]) for disruptive children were found to be "possibly efficacious", as they were effective; however, there is scope for improvement regarding the quality of trials. Arrays of other treatments are considered experimental. A few other therapies with questionable efficacy have also been reported. Interestingly, assertiveness training and rational emotive BT, which were probably efficacious according to previous reviews, were relegated to "experimental" and "possibly efficacious" groups, respectively, based on recent research. Another CBT-based model, "anger-control training", which was drifting down the evidence-base efficacy list in two consecutive reviews, was marked as a therapy with questionable efficacy in disruptive-disorder children. ${ }^{12,113}$ CBT and PMT are considered to be management of anger, irritability, and aggressiveness, which can be viewed as a transdiagnostic approach in children with these problems. ${ }^{114}$

Recent studies have also explored the biological moderation effect on treatment response in oppositional children. One recent review concluded that the presence of callous unemotional traits in children is associated with poor treatment outcomes, but at the same time indicated that social learning-based parent training was capable of producing lasting improvement in callous unemotional traits, particularly when delivered early in childhood. ${ }^{115}$ Another study showed higher cortisol stress reactivity and better cortisol recovery were predictors of reduction in aggression, along with PMT intervention. ${ }^{83} \mathrm{~A}$ positive moderation effect of $D R D 448$-base pair seven-repeat 
sequences in comparison with four-repeat sequences on good parenting practices in externalizing disorder children is another example of such effects. ${ }^{55,56}$

\section{Pharmacotherapy management}

With regard to treatment of maladaptive aggression in youth, psychosocial approaches are the first line of intervention, as these have no side-effect burden. ${ }^{98}$ When aggression of an oppositional child cannot be managed psychosocially, pharmacotherapy can be combined to have better results, especially on aggression and emotion dysregulation domains. ${ }^{116}$ Treatment of comorbid disorders is the first option in pharmacotherapy. If the disorder is still not controlled, an atypical antipsychotic can be added, which can be titrated to get the ideal dose schedule. In cases of nonresponse to medication, the antipsychotic can be changed. If a partial response occurs, a mood stabilizer can be added to the existing antipsychotic, but combination of more than one antipsychotic is not recommended. Also, regular side-effect monitoring is recommended for the young person, among which weight gain and sedation are most prominent. ${ }^{98}$

Among the medications, methylphenidate has the best results against aggression when there is comorbid ADHD. Nonstimulants like atomoxetine, guanfacine, and clonidine have good effects, among which atomoxetine has the best results, followed by guanfacine in cases of associated ADHD, but studies concerning these medications have not focused specifically on aggression as an outcome. As such, these treatments can be viewed as second line in the list of antiaggression medications. ${ }^{117}$

Among atypical antipsychotics, risperidone has the strongest evidence in the treatment of aggression and irritability in youth, followed by aripiprazole, which is equivalent to risperidone according to some studies. ${ }^{118}$ Quetiapine also has a large magnitude of effect, but more side-effect concerns and the poor quality of available studies put it out of favor. Typical antipsychotics like haloperidol have shown variable effects on aggression across studies. As such, it is not favored in aggressive children either. Among mood stabilizers, valproate, lithium has both side-effect concerns and weak study-quality issues, but its effects are large. Therefore, both have conditionally recommended, while valproate is preferred over lithium. Carbamazepine has not proven to be effective in aggression in children. ${ }^{119}$

A recent review discussed the pharmacological treatment options of DMDD, which has already been shown to have close resemblance with ODD. ${ }^{31}$ In the very few trials that exist, methylphenidate is effective and not lithium in

Box I Treatment options for oppositional defiant disorder (ODD)

\section{Treatment options for ODD}

Psychosocial management is the mainstay. Active components are as follows:

1. Parental management training

2. In schools, teachers' training for behavioral interventions

3. Peer group support and peer-mediated intervention

4. Social awareness and supervision

5. Cognitive behavior therapy: perspective taking, problem-solving skills training, assertive training, anger management training

6. Functional family therapy or brief strategic family therapy

\section{Pharmacotherapy}

For management of comorbidities:

- According to the existing protocol for comorbidities

- Methylphenidate has best evidence followed by atomoxetine, and guanfacine SR, clonidine for ADHD with behavior problems

For management of aggression:

- Antipsychotic (risperidone followed by aripiprazole has the best evidence, followed by other atypical and typical antipsychotics)

- In cases of partial response, mood stabilizer can be added

- For no response, antipsychotic can be changed

Abbreviations: ADHD, attention-deficit/hyperactivity disorder; SR, sustained release. 
diagnosed DMDD patients. In SMD patients, lithium seems to have the best positive evidence (ahead of valproate) among mood stabilizers. Carbamazepine and lamotrigine have not had any positive trials. Among antipsychotics, haloperidol and thioridazine have shown positive results. Risperidone and aripiprazole are approved for the treatment of irritability. Quetiapine has also been observed to have a beneficial effect on aggression. Methylphenidate is effective. Interestingly, clonidine and guanfacine are also effective in the treatment of aggression, but not atomoxetine. Antidepressants, including bupropion, desipramine, and fluoxetine, have a cumulativeeffect size of 0.3 considering overall improvement in ADHD as outcome, not only aggression (Box 1). ${ }^{117}$

\section{Conclusion}

Though initially conceptualized as a disorder to explain some wayward behaviors, ODD has evolved into a recognized disorder with significant biological correlates. It is closely related to but a separate disorder from ADHD, as proven by clinical and temperamental antecedents, functional consequences, and biological research. Recent research has shown that ODD may not be a unitary concept. ODD might have two separate symptom dimensions: affective and behavioral. These conceptualizations need further detailed research in the biological and epidemiological fields for further exploration. Treatment of ODD needs further research. Psychosocial treatments continue to be time-tested and effective in this group. However, with strong biological correlates, some effective pharmacotherapeutic management can be explored, especially that focusing on the serotonergic system.

\section{Disclosure}

The authors report no conflicts of interest in this work.

\section{References}

1. American Psychiatric Association. Diagnostic and Statistical Manual of Mental Disorders. 5th ed. Arlington, VA: APA; 2013.

2. American Psychiatric Association. Diagnostic and Statistical Manual of Mental Disorders. 2nd ed. Arlington, VA: APA; 1972.

3. Jenkins RL, Boyer A. Types of delinquent behavior and background factors. Int J Soc Psychiatry. 1968;14(1):65-76.

4. Quay HC. Dimensions of personality in delinquent boys as inferred from the factor analysis of case history data. Child Dev. 1964;35(2):479-484.

5. American Psychiatric Association. Diagnostic and Statistical Manual of Mental Disorders. 3rd ed. Arlington, VA: APA; 1980.

6. Mattison R, Cantwell DP, Russell AT, Will L. A comparison of DSM-II and DSM-III in the diagnosis of childhood psychiatric disorders - II: interrater agreement. Arch Gen Psychiatry. 1979;36(11):1217-1222.

7. Rutter M, Shaffer D. DSM-III: a step forward or back in terms of the classification of child psychiatric disorders? J Am Acad Child Psychiatry. 1980;19(3):371-394.
8. Achenbach TM. DSM-III in light of empirical research on the classification of child psychopathology. J Am Acad Child Psychiatry. 1980;19(3):395-412.

9. Rey JM, Bashir MR, Schwarz M, Richards IN, Plapp JM, Stewart GW. Oppositional disorder: fact or fiction? J Am Acad Child Adolesc Psychiatry. 1988;27(2):157-162.

10. Spitzer RL, Davies M, Barkley RA. The DSM-III-R field trial of disruptive behavior disorders. J Am Acad Child Adolesc Psychiatry. 1990;29(5):690-697.

11. Frick PJ, Lahey BB, Applegate B, et al. DSM-IV field trials for the disruptive behavior disorders: symptom utility estimates. J Am Acad Child Adolesc Psychiatry. 1994;33(4):529-539.

12. Lahey BB, Applegate B, Barkley RA, et al. DSM-IV field trials for oppositional defiant disorder and conduct disorder in children and adolescents. Am J Psychiatry. 1994;151(8):1163-1171.

13. Cohen P, Cohen J, Brook J. An epidemiological study of disorders in late childhood and adolescence - II: persistence of disorders. J Child Psychol Psychiatry. 1993;34(6):869-877.

14. World Health Organization. The ICD-10 Classification of Mental and Behavioural Disorders. Geneva: WHO; 1994.

15. Farrington DP, Loeber R, Van Kammen WB. Long-term criminal outcomes of hyperactivity-impulsivity-attention deficit and conduct problems in childhood. In: Robins LN, Rutter M, editors. Straight and Devious Pathways from Childhood to Adulthood. New York: Cambridge University Press; 1990.

16. Rowe R, Maughan B, Pickles A, Costello EJ, Angold A. The relationship between DSM-IV oppositional defiant disorder and conduct disorder: findings from the Great Smoky Mountains Study. J Child Psychol Psychiatry. 2002;43(3):365-373.

17. Keenan K, Wroblewski K, Hipwell A, Loeber R, Stouthamer-Loeber M. Age of onset, symptom threshold, and expansion of the nosology of conduct disorder for girls. J Abnorm Psychol. 2010;119(4):689-698.

18. Rowe R, Costello EJ, Angold A, Copeland WE, Maughan B. Developmental pathways in oppositional defiant disorder and conduct disorder. J Abnorm Psychol. 2010;119(4):726-738.

19. Burke JD, Waldman I, Lahey BB. Predictive validity of childhood oppositional defiant disorder and conduct disorder: implications for the DSM-V. J Abnorm Psychol. 2010;119(4):739-751.

20. Kolko DJ, Pardini DA. ODD dimensions, ADHD, and callousunemotional traits as predictors of treatment response in children with disruptive behavior disorders. J Abnorm Psychol. 2010;119(4): 713-725.

21. Mikolajewski AJ, Taylor J, Iacono WG. Oppositional defiant disorder dimensions: genetic influences and risk for later psychopathology. $J$ Child Psychol Psychiatry. 2017;58(6):702-710.

22. Stringaris A, Goodman R. Three dimensions of oppositionality in youth. J Child Psychol Psychiatry. 2009;50(3):216-223.

23. Farrington DP, Loeber R, Stouthamer-Loeber M, Kammen WB, Schmidt L. Self-reported delinquency and a combined delinquency seriousness scale based on boys, mothers, and teachers: concurrent and predictive validity for African-Americans and Caucasians. Criminology. 1996;34(4):493-517.

24. Loeber R, Burke JD, Lahey BB, Winters A, Zera M. Oppositional defiant and conduct disorder: a review of the past 10 years - part I. J Am Acad Child Adolesc Psychiatry. 2000;39(12):1468-1484.

25. Fergusson DM, Boden JM, Horwood LJ. Classification of behavior disorders in adolescence: scaling methods, predictive validity, and gender differences. J Abnorm Psychol. 2010;119(4):699-712.

26. Stringaris A, Maughan B, Goodman R. What's in a disruptive disorder? Temperamental antecedents of oppositional defiant disorder: findings from the Avon longitudinal study. J Am Acad Child Adolesc Psychiatry. 2010;49(5):474-483.

27. Axelson D, Findling RL, Fristad MA, et al. Examining the proposed disruptive mood dysregulation disorder diagnosis in children in the Longitudinal Assessment of Manic Symptoms Study. J Clin Psychiatry. 2012;73(10):1342-1350. 
28. Dougherty LR, Smith VC, Bufferd SJ, Kessel EM, Carlson GA, Klein DN. Disruptive mood dysregulation disorder at the age of 6 years and clinical and functional outcomes 3 years later. Psychol Med. 2016;46(05):1103-1114.

29. Dougherty LR, Smith VC, Bufferd SJ, et al. DSM-5 disruptive mood dysregulation disorder: correlates and predictors in young children. Psychol Med. 2014;44(11):2339-2350.

30. Freeman AJ, Youngstrom EA, Youngstrom JK, Findling RL. Disruptive mood dysregulation disorder in a community mental health clinic: prevalence, comorbidity and correlates. J Child Adolesc Psychopharmacol. 2016;26(2):123-130.

31. Mayes SD, Waxmonsky JD, Calhoun SL, Bixler EO. Disruptive mood dysregulation disorder symptoms and association with oppositional defiant and other disorders in a general population child sample. J Child Adolesc Psychopharmacol. 2016;26(2):101-106.

32. Nock MK, Kazdin AE, Hiripi E, Kessler RC. Lifetime prevalence, correlates, and persistence of oppositional defiant disorder: results from the National Comorbidity Survey Replication. J Child Psychol Psychiatry. 2007;48(7):703-713.

33. Waschbusch DA, King S. Should sex-specific norms be used to assess attention-deficit/hyperactivity disorder or oppositional defiant disorder? J Consult Clin Psychol. 2006;74(1):179-185.

34. Harvey EA, Breaux RP, Lugo-Candelas CI. Early development of comorbidity between symptoms of attention-deficit/hyperactivity disorder (ADHD) and oppositional defiant disorder (ODD). J Abnorm Psychol. 2016;125(2):154-167.

35. Kim HW, Cho SC, Kim BN, Kim JW, Shin MS, Yeo JY. Does oppositional defiant disorder have temperament and psychopathological profiles independent of attention deficit/hyperactivity disorder? Compr Psychiatry. 2010;51(4):412-418.

36. Fite PJ, Evans SC, Cooley JL, Rubens SL. Further evaluation of associations between attention-deficit/hyperactivity and oppositional defiant disorder symptoms and bullying-victimization in adolescence. Child Psychiatry Hum Dev. 2014;45(1):32-41.

37. Luciano M. The ICD-11 beta draft is available online. World Psychiatry. 2015;14(3):375-376.

38. Evans SC, Burke JD, Roberts MC, et al. Irritability in child and adolescent psychopathology: an integrative review for ICD-11. Clin Psychol Rev. 2017;53:29-45.

39. Gottesman II, Gould TD. The endophenotype concept in psychiatry: etymology and strategic intentions. Am J Psychiatry. 2003;160(4):636-645.

40. Morris SE, Cuthbert BN. Research domain criteria: cognitive systems, neural circuits, and dimensions of behavior. Dialogues Clin Neurosci. 2012;14(1):29-37.

41. Polderman TJ, Benyamin B, de Leeuw CA, et al. Meta-analysis of the heritability of human traits based on fifty years of twin studies. Nat Genet. 2015;47(7):702-709.

42. Krueger RF, Hicks BM, Patrick CJ, Carlson SR, Iacono WG, McGue M. Etiologic connections among substance dependence, antisocial behavior and personality: modeling the externalizing spectrum. $J$ Abnorm Psychol. 2002;111(3):411-424.

43. Coolidge FL, Thede LL, Young SE. Heritability and the comorbidity of attention deficit hyperactivity disorder with behavioral disorders and executive function deficits: a preliminary investigation. Dev Neuropsychol. 2000;17(3):273-287.

44. Lahey BB, Waldman ID. Annual research review: phenotypic and causal structure of conduct disorder in the broader context of prevalent forms of psychopathology. J Child Psychol Psychiatry. 2012;53(5):536-557.

45. Jain M, Palacio LG, Castellanos FX, et al. Attention-deficit/ hyperactivity disorder and comorbid disruptive behavior disorders: evidence of pleiotropy and new susceptibility loci. Biol Psychiatry. 2007;61(12):1329-1339.

46. Anney RJ, Lasky-Su J, O’Dúshláine C, et al. Conduct disorder and ADHD: evaluation of conduct problems as a categorical and quantitative trait in the international multicentre ADHD genetics study. Am J Med Genet B Neuropsychiatr Genet. 2008;147B(8):1369-1378.
47. Pappa I, St Pourcain B, Benke K, et al. A genome-wide approach to children's aggressive behavior: the EAGLE consortium. Am J Med Genet B Neuropsychiatr Genet. 2016;171(5):562-572.

48. Salvatore JE, Dick DM. Genetic influences on conduct disorder Neurosci Biobehav Rev. Epub 2016 Jun 24.

49. Dick DM, Aliev F, Latendresse S, et al. How phenotype and developmental stage affect the genes we find: GABRA2 and impulsivity. Twin Res Hum Genet. 2013;16(3):661-669.

50. Veroude K, Zhang-James Y, Fernàndez-Castillo N, Bakker MJ, Cormand B, Faraone SV. Genetics of aggressive behavior: an overview. Am J Med Genet B Neuropsychiatr Genet. 2016;171B(1):3-43.

51. Ficks $C A$, Waldman ID. Candidate genes for aggression and antisocial behavior: a meta-analysis of association studies of the 5HTTLPR and MAOA-uVNTR. Behav Genet. 2014;44(5):427-444.

52. Zhang-James Y, Faraone SV. Genetic architecture for human aggression: a study of gene-phenotype relationship in OMIM. Am J Med Genet B Neuropsychiatr Genet. 2016;171(5):641-649.

53. Bakermans-Kranenburg MJ, van Ijzendoorn MH. The hidden efficacy of interventions: genexenvironment experiments from a differential susceptibility perspective. Annu Rev Psychol. 2015;66:381-409.

54. Grady DL, Chi HC, Ding YC, et al. High prevalence of rare dopamine receptor D4 alleles in children diagnosed with attention-deficit hyperactivity disorder. Mol Psychiatry. 2003;8(5):536-545.

55. Belsky J, Pluess M. Genetic moderation of early child-care effects on social functioning across childhood: a developmental analysis. Child Dev. 2013;84(4):1209-1225.

56. King AP, Muzik M, Hamilton L, Taylor AB, Rosenblum KL, Liberzon I. Dopamine receptor gene DRD4 7-repeat allele X maternal sensitivity interaction on child externalizing behavior problems: independent replication of effects at 18 months. PLoS One. 2016;11(8):e0160473.

57. Cecil CA, Lysenko LJ, Jaffee SR, et al. Environmental risk, oxytocin receptor gene (OXTR) methylation and youth callousunemotional traits: a 13-year longitudinal study. Mol Psychiatry. 2014;19(10):1071-1077.

58. Noordermeer SD, Luman M, Oosterlaan J. A systematic review and meta-analysis of neuroimaging in oppositional defiant disorder (ODD) and conduct disorder (CD) taking attention-deficit hyperactivity disorder (ADHD) into account. Neuropsychol Rev. 2016;26(1):44-72.

59. Blair RJ, Lee TM. The social cognitive neuroscience of aggression, violence, and psychopathy. Soc Neurosci. 2013;8(2):108-111.

60. Diamond A. Executive functions. Annu Rev Psychol. 2013;64:135-168.

61. Rubia K. "Cool" inferior frontostriatal dysfunction in attentiondeficit/hyperactivity disorder versus "hot" ventromedial orbitofrontallimbic dysfunction in conduct disorder: a review. Biol Psychiatry. 2011;69(12):e69-e87.

62. Ashburner J, Friston KJ. Voxel-based morphometry: the methods. Neuroimage. 2000;11(6 Pt 1):805-821.

63. Mechelli A, Price CJ, Friston KJ, Ashburner J. Voxel-based morphometry of the human brain: methods and applications. Curr Med Imaging Rev. 2005;1(2):105-113.

64. Whitwell JL. Voxel-based morphometry: an automated technique for assessing structural changes in the brain. J Neurosci. 2009;29(31):9661-9664.

65. Puzzo I, Smaragdi A, Gonzalez K, Martin-Key N, Fairchild G. Neurobiological, neuroimaging, and neuropsychological studies of children and adolescents with disruptive behavior disorders: neurobiology of child disruptive behaviors. Fam Relat. 2016;65(1):134-150.

66. Bethlehem RA, Romero-Garcia R, Mak E, Bullmore ET, Baron-Cohen S. Structural covariance networks in children with autism or ADHD Cereb Cortex. 2017;27(8):4267-4276.

67. Fairchild G, Toschi N, Sully K, et al. Mapping the structural organization of the brain in conduct disorder: replication of findings in two independent samples. J Child Psychol Psychiatry. 2016;57(9):1018-1026.

68. Fischl B. FreeSurfer. Neuroimage. 2012;62(2):774-781.

69. Fahim C, He Y, Yoon U, Chen J, Evans A, Pérusse D. Neuroanatomy of childhood disruptive behavior disorders. Aggress Behav. 2011;37(4):326-337. 
70. Fairchild G, Hagan CC, Passamonti L, Walsh ND, Goodyer IM, Calder AJ. Atypical neural responses during face processing in female adolescents with conduct disorder. J Am Acad Child Adolesc Psychiatry. 2014;53(6):677-687.e5.

71. Passamonti L, Fairchild G, Goodyer IM, et al. Neural abnormalities in early-onset and adolescence-onset conduct disorder. Arch Gen Psychiatry. 2010;67(7):729-738.

72. Decety J, Michalska KJ, Akitsuki Y, Lahey BB. Atypical empathic responses in adolescents with aggressive conduct disorder: a functional MRI investigation. Biol Psychol. 2009;80(2):203-211.

73. Sarkar S, Craig MC, Catani M, et al. Frontotemporal white-matter microstructural abnormalities in adolescents with conduct disorder: a diffusion tensor imaging study. Psychol Med. 2013;43(2):401-411.

74. Zhang J, Gao J, Shi H, et al. Sex differences of uncinate fasciculus structural connectivity in individuals with conduct disorder. Biomed Res Int. 2014;2014:673165.

75. Haney-Caron E, Caprihan A, Stevens MC. DTI-measured white matter abnormalities in adolescents with conduct disorder. $J$ Psychiatr Res. 2014;48(1):111-120.

76. Finger EC, Marsh A, Blair KS, et al. Impaired functional but preserved structural connectivity in limbic white matter tracts in youth with conduct disorder or oppositional defiant disorder plus psychopathic traits. Psychiatry Res Neuroimaging. 2012;202(3):239-244.

77. Zhou J, Yao N, Fairchild G, et al. Disrupted default mode network connectivity in male adolescents with conduct disorder. Brain Imaging Behav. 2016;10(4):995-1003.

78. Scott S. Oppositional and conduct disorders. In: Thapar A, Pine DS, Leckman JF, Scott S, Snowling MJ, Taylor EA. Rutter's Child and Adolescent Psychiatry. 6th ed. New Jersey, USA: Wiley-Blackwell; 2015:913-930.

79. Serafini G, Pompili M, Borgwardt S, et al. Brain changes in early-onset bipolar and unipolar depressive disorders: a systematic review in children and adolescents. Eur ChildAdolesc Psychiatry. 2014;23(11):1023-1041.

80. Lorber MF. Psychophysiology of aggression, psychopathy, and conduct problems: a meta-analysis. Psychol Bull. 2004;130(4):531-552.

81. van Goozen SH, Fairchild G, Harold GT. The role of neurobiological deficits in childhood antisocial behavior. Curr Dir Psychol Sci. 2008;17(3):224-228.

82. van Goozen SH, Matthys W, Cohen-Kettenis PT, Gispen-de Wied C, Wiegant VM, van Engeland H. Salivary cortisol and cardiovascular activity during stress in oppositional-defiant disorder boys and normal controls. Biol Psychiatry. 1998;43(7):531-539.

83. Schoorl J, van Rijn S, de Wied M, van Goozen SH, Swaab H. Neurobiological stress responses predict aggression in boys with oppositional defiant disorder/conduct disorder: a 1-year follow-up intervention study. Eur Child Adolesc Psychiatry. 2017;26(7):805-813.

84. Laurent HK, Gilliam KS, Wright DB, Fisher PA. Child anxiety symptoms related to longitudinal cortisol trajectories and acute stress responses: evidence of developmental stress sensitization. J Abnorm Psychol. 2015;124(1):68-79.

85. Stadler C, Schmeck K, Nowraty I, Müller WE, Poustka F. Platelet 5-HT uptake in boys with conduct disorder. Neuropsychobiology. 2004;50(3):244-251

86. Zepf FD, Gaber TJ, Bubenzer S, et al. Reduced central nervous 5-HT neurotransmission in youth with ADHD influences ratings of a virtual opponents' extraversion: effects of trait-aggression. J Pediatr Sci. 2011;3(2):e73.

87. Arias JM, Acosta CA, Valencia JG, et al. Exploring epistasis in candidate genes for antisocial personality disorder. Psychiatr Genet. 2011;21(3):115-124.

88. Matthys W, Vanderschuren LJ, Schutter DJ, Lochman JE. Impaired neurocognitive functions affect social learning processes in oppositional defiant disorder and conduct disorder: implications for interventions. Clin Child Fam Psychol Rev. 2012;15(3):234-246.

89. Griffith SF, Arnold DH, Rolon-Arroyo B, Harvey EA. Neuropsychological predictors of ODD symptom dimensions in young children. J Clin Child Adolesc Psychol. Epub 2017 Jan 12.
90. Aebi M, Plattner B, Metzke CW, Bessler C, Steinhausen HC. Parentand self-reported dimensions of oppositionality in youth: construct validity, concurrent validity, and the prediction of criminal outcomes in adulthood. J Child Psychol Psychiatry. 2013;54(9):941-949.

91. Card NA, Little TD. Proactive and reactive aggression in childhood and adolescence: a meta-analysis of differential relations with psychosocial adjustment. Int J Behav Dev. 2006;30(5):466-480.

92. Boivin M, Brendgen M, Vitaro F, et al. Evidence of gene-environment correlation for peer difficulties: disruptive behaviors predict early peer relation difficulties in school through genetic effects. Dev Psychopathol. 2013;25(1):79-92.

93. Pardini D, Frick PJ. Multiple developmental pathways to conduct disorder: current conceptualizations and clinical implications. J Can Acad Child Adolesc Psychiatry. 2013;22(1):20-25.

94. Caspi A, Moffitt TE. Gene-environment interactions in psychiatry: joining forces with neuroscience. Nat Rev Neurosci. 2006;7(7):583-590.

95. Plomin R, Daniels D. Why are children in the same family so different from one another? Int J Epidemiol. 2011;40(3):563-582.

96. Nathan PE, Gorman JM. A Guide to Treatments That Work. 4th ed. Oxford, NY: Oxford University Press; 2015.

97. Knapp P, Chait A, Pappadopulos E, Crystal S, Jensen PS. Treatment of maladaptive aggression in youth - CERT guidelines I: engagement, assessment, and management. Pediatrics. 2012;129(6): e1562-e1576.

98. Rosato NS, Correll CU, Pappadopulos E, et al. Treatment of maladaptive aggression in youth - CERT guidelines II: treatments and ongoing management. Pediatrics. 2012;129(6):e1577-e1586.

99. Sanders MR. Development, evaluation, and multinational dissemination of the Triple P positive parenting program. Annu Rev Clin Psychol. 2012;8:345-379.

100. Forgatch MS, Patterson GR, Gewirtz AH. Looking forward: the promise of widespread implementation of parent training programs. Perspect Psychol Sci. 2013;8(6):682-694.

101. Scott S, O'Connor TG, Futh A, Matias C, Price J, Doolan M. Impact of a parenting program in a high-risk, multi-ethnic community: the PALS trial. J Child Psychol Psychiatry. 2010;51(12):1331-1341.

102. Graziano PA, Bagner DM, Slavec J, et al. Feasibility of intensive parent-child interaction therapy (I-PCIT): results from an open trial. J Psychopathol Behav Assess. 2015;37(1):38-49.

103. Kleinman KE, Saigh PA. The effects of the good behavior game on the conduct of regular education New York City high school students. Behav Modif. 2011;35(1):95-105.

104. Webster-Stratton C, Reid MJ. A multifaceted treatment approach for young children with conduct problems. In: Kazdin AE, Weisz JR, editors. Evidence-Based Psychotherapies for Children and Adolescents. 3rd ed. New York: Guildford; 2017:122-141.

105. Gavita OA, Celin A. Rational stories versus rational parenting program for the treatment of child psychopathology: efficacy of two formats of rational-emotive behavior therapy. J Cogn Behav Psychother. 2013;13(1):33-56

106. Lochman JE, Lenhart LA. Anger coping intervention for aggressive children: conceptual models and outcome effects. Clin Psychol Rev. 1993;13(8):785-805.

107. Lochman JE, Wells KC. The Coping Power program for preadolescent aggressive boys and their parents: outcome effects at the 1-year followup. J Consult Clin Psychol. 2004;72(4):571-578.

108. Lochman JE, Wells KC. Effectiveness of the Coping Power program and of classroom intervention with aggressive children: outcomes at a 1-year follow-up. Behav Ther. 2003;34(4):493-515.

109. Lochman JE, Wells KC. Contextual social-cognitive mediators and child outcome: a test of the theoretical model in the Coping Power program. Dev Psychopathol. 2002;14(4):945-967.

110. Leijten P, Raaijmakers MAJ, de Castro BO, van den Ban E, Matthys W. Effectiveness of the Incredible Years parenting program for families with socioeconomically disadvantaged and ethnic minority backgrounds. J Clin Child Adolesc Psychol. 2017;46(1):59-73. 
111. McCart MR, Sheidow AJ. Evidence-based psychosocial treatments for adolescents with disruptive behavior. J Clin Child Adolesc Psychol. 2016;45(5):529-563.

112. Brestan EV, Eyberg SM. Effective psychosocial treatments of conductdisordered children and adolescents: 29 years, 82 studies, and 5,272 kids. J Clin Child Psychol. 1998;27(2):180-189.

113. Eyberg SM, Nelson MM, Boggs SR. Evidence-based psychosocial treatments for children and adolescents with disruptive behavior. J Clin Child Adolesc Psychol. 2008;37(1):215-237.

114. Sukhodolsky DG, Smith SD, McCauley SA, Ibrahim K, Piasecka JB. Behavioral interventions for anger, irritability, and aggression in children and adolescents. J Child Adolesc Psychopharmacol. 2016;26(1):58-64.

115. Hawes DJ, Price MJ, Dadds MR. Callous-unemotional traits and the treatment of conduct problems in childhood and adolescence: a comprehensive review. Clin Child Fam Psychol Rev. 2014;17(3):248-267.
116. Masi G, Milone A, Manfredi A, Brovedani P, Pisano S, Muratori P. Combined pharmacotherapy-multimodal psychotherapy in children with disruptive behavior disorders. Psychiatry Res. 2016;238:8-13.

117. Tourian L, LeBoeuf A, Breton JJ, et al. Treatment options for the cardinal symptoms of disruptive mood dysregulation disorder. J Can Acad Child Adolesc Psychiatry. 2015;24(1):41-54.

118. Safavi P, Hasanpour-Dehkordi A, Ahmadi MA. Comparison of risperidone and aripiprazole in the treatment of preschool children with disruptive behavior disorder and attention deficit-hyperactivity disorder: a randomized clinical trial. JAdv Pharm Technol Res. 2016;7(2):43-47.

119. Gorman DA, Gardner DM, Murphy AL, et al. Canadian guidelines on pharmacotherapy for disruptive and aggressive behavior in children and adolescents with attention-deficit hyperactivity disorder, oppositional defiant disorder, or conduct disorder. Can J Psychiatry. 2015;60(2):62-76.
Psychology Research and Behavior Management

\section{Publish your work in this journal}

Psychology Research and Behavior Management is an international, peerreviewed, open access journal focusing on the science of psychology and its application in behavior management to develop improved outcomes in the clinical, educational, sports and business arenas. Specific topics covered in the journal include: Neuroscience, memory and decision making; Behavio

\section{Dovepress}

modification and management; Clinical applications; Business and sports performance management; Social and developmental studies; Animal studies. The manuscript management system is completely online and includes a very quick and fair peer-review system, which is all easy to use. Visit http://www. dovepress.com/testimonials.php to read real quotes from published authors.

Submit your manuscript here: https://www.dovepress.com/psychology-research-and-behavior-management-journal 